\title{
Development and pilot of a tool to measure the healthiness of the in-store food environment
}

\author{
Rachael Jaenke ${ }^{1, *}$, Christel van den Boogaard ${ }^{1}$ Emma McMahon ${ }^{1}$ and \\ Julie Brimblecombe ${ }^{1,2}$ \\ 'Wellbeing and Preventable Chronic Disease Division, Menzies School of Health Research, Charles Darwin University, \\ Casuarina, Northern Territory, Australia: ${ }^{2}$ Department of Nutrition, Dietetics and Food, Faculty of Medicine, Nursing \\ and Health Sciences, Monash University, Notting Hill, Victoria, Australia
}

Submitted 2 October 2019: Final revision received 23 April 2020: Accepted 1 June 2020: First published online 13 August 2020

\begin{abstract}
Objective: To rigorously develop a tool which enables rapid yet comprehensive appraisal of the consumer food retail environment and provision of real-time feedback to store managers and owners, based on the '4Ps' principles of marketing. Design: Multi-stage iterative approach including (1) Systematic literature review; (2) Stakeholder consultation; (3) Assessment of existing tools against identified needs; (4) Tool development; (5) Pilot testing and (6) Transition of tool to mobile application (the Store Scout app).

Setting: Northern Territory, Australia.

Participants: Nine remote Aboriginal community food stores; public health nutritionists, retailers, store board directors, Aboriginal community members, government representatives.

Results: Forty-seven existing tools and thirty-four stakeholder interviews informed the development of the current instrument, which comprised: (1) seven product categories (Fruit \& Vegetables, Drinks, Snack Foods, Meals \& Convenience Foods, Meat \& Seafood, Dairy \& Eggs, Breads \& Cereals) across the '4Ps' (Product, Placement, Price, Promotion); (2) Store manager questions about context and perceived importance of key principles about the store environment and (3) a scoring and feedback component. The tool was considered feasible and acceptable by all testers.

Conclusions: The developed tool addresses an unmet need to measure the consumer food retail environment across all 4Ps whilst also incorporating manager perspectives and immediate feedback. Our objectives of developing a comprehensive, feasible and acceptable instrument were achieved during pilot testing. The tool will support implementation of best practice within stores to encourage healthy food choices and has potential for broad application in retail settings locally and internationally, as well as for research purposes.
\end{abstract}

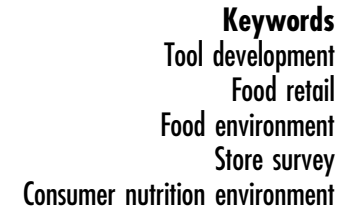

Keywords Food retail Store survey Consumer nutrition environment
The local food environment, comprising the community and in-store food retail environments, is a key determinant of food choice and dietary behaviour ${ }^{(1,2)}$. The ' 4 Ps' of marketing (product, price, placement and promotion) influence purchasing behaviour, and modifications to any or all of these in the food retail setting may improve healthy food choices and decrease purchasing of less healthy products ${ }^{(3)}$. In the context of the in-store food retail environment, 'product' refers to availability or range of healthier options; 'promotion' includes shelf labels or signage, as well as displays or demonstrations; 'price' relates to discounts and deals, price increases or subsidies; and 'placement' includes store layout or shelf space/ location $^{(4)}$.

Valid and reliable measures of in-store food retail environments are necessary to assess their relationship to diet and health and to inform strategies for dietary improvement. Several tools exist to measure elements of the in-store food retail environment that relate to one or more of the $4 \mathrm{Ps}^{(5)}$. Gittelsohn \& Sharma ${ }^{(6)}$ have suggested that inclusion of all elements which could be measured is likely to be impractical and exceed the purpose of providing a 
measure of how the store environment supports or does not support healthy food choices. As existing instruments may have been developed for a specific purpose and not be applicable to a range of settings, Gittelsohn \& Sharma ${ }^{(6)}$ recommend that formative research be conducted to inform the use of an instrument which is focused and meets its intended purpose.

In Australia, supermarkets play a key role in population health as they are the primary source of food, and in remote areas of Australia, where there may only be a single supermarket or store and no other food retailers, these establishments are integral to the community food system $^{(7)}$.

The Good Food Planning Tool ${ }^{(7)}$ was previously developed by our team to support a multi-sectoral continuous improvement approach to enhancing the performance of the food system in remote Aboriginal and Torres Strait Islander communities to address food security. One of five domains of the Good Food Planning Tool is the food businesses domain, which articulates best practice in food retail to ensure a healthy, affordable and accessible food supply. Best practice areas include 'Promotion and Placement', 'Prices', Product', 'Places (buildings)', 'Policies and management support', 'People in food businesses' and 'Community support'. The Good Food Planning Tool was designed for use by stakeholders to appraise best practice performance and develop an action plan to achieve incremental improvement in each of the food system domains. Through use of this tool with four remote community intersectoral stakeholder groups, we identified that a tool to provide an objective rapid appraisal of the healthiness of the community store environment would complement such a process.

To our knowledge, there are no existing tools available which comprehensively measure all 4Ps of marketing and which are evidence-based and tailored to remote Australian Aboriginal and Torres Strait Islander community stores. Therefore, we aimed to develop a tool to facilitate the rapid appraisal of the in-store food retail environment in remote Aboriginal community stores in Australia.

This paper describes the development of this tool, which followed a multi-stage iterative approach of needs assessment, tool development and pilot testing, and transition to mobile application. Needs assessment involved identifying existing tools through systematic literature review (Step 1) and stakeholder consultation (Step 2) to determine if existing tools met identified needs (Step 3). As no existing tools met identified needs, we proceeded with tool development; we developed a tool (Step 4) based on synthesised findings from Steps 1 and 2 and existing best practice/current practice (e.g. national guidelines, remote store policies). We pilot tested this tool to assess feasibility and acceptability (Step 5), and, based on the results of this pilot testing, developed the tool into a mobile app (Step 6).

\section{Methods and results}

\section{Setting}

Approximately $19 \%$ of Aboriginal and Torres Strait Islander people reside in communities located in remote or very remote Australia, many of which have less than 1000 residents $^{(8)}$.

In these locations, the community store is the primary source of food ${ }^{(7)}$. These stores, in the majority of cases, are owned by the community and governed by a locally elected board of directors and can be classified as smallto medium-sized retail businesses or supermarkets, which supply a range of food products and other household goods.

A number of these stores have nutrition policies that outline strategies relating to the $4 \mathrm{Ps}^{(9,10)}$. These have supported improvements to the range of healthier products available and reduced prices of fresh fruit, vegetables and bottled water ${ }^{(11)}$. Alongside healthenabling initiatives however, ready-to-eat, energy-dense, nutrient-poor discretionary foods have been made increasingly available, in both remote and non-remote stores $^{(12)}$. This is of concern as these foods displace more nutritious foods from the diet ${ }^{(13)}$. An unhealthy diet is one of the leading risk factors for non-communicable diseases $^{(14)}$, of which Aboriginal and Torres Strait Islander Peoples in remote Australia experience excess burden $^{(15)}$.

In the Northern Territory (NT) of Australia, where approximately $54 \%$ of the NT Aboriginal and Torres Strait Islander population reside in very remote communities $^{(8)}$, the Australian Government Community Store Licencing legislation under the Stronger Futures in the Northern Territory Act (2012) stipulates the availability of a core range of foods in stores in an effort to ensure the quality of the food supply(16), which is monitored by Australian Government Stores Licencing representatives using the Food Security Report Licence Compliance \& Store Audit Checklist ${ }^{(17)}$. Dietitians (Public Health Nutritionists - hereafter PHN) employed by the NT government or Aboriginal Community Controlled Health Services may support community stores in health promotion initiatives as part of their nutrition service to communities, and participate in annual monitoring of stores through the Market Basket Survey ${ }^{(18)}$, which addresses elements of Product (availability, quality, variety) and Price (the cost of a healthy basket of food and other household items). Placement and promotion practices are not formally evaluated as no tools exist for this purpose.

There has been interest from stakeholders, including public health practitioners, retailers (including Aboriginal and Torres Strait Islander store owners) and Australian government store licencing officers, to explore these elements in remote community stores in order to better inform their practice within this setting. 
The method undertaken and results for each of the six steps that comprised tool development are described below.

\section{Step 1. Systematic literature review}

\section{Methods}

A systematic literature review was conducted in March 2014 to identify existing tools which assess the in-store food environment. Our aims of this review were to identify, for existing tools, (i) which elements of the store environment are assessed and how they are measured and rated/ evaluated, (ii) measures of robustness (i.e. validity and reliability) and (iii) measures of store manager perspectives on their retail practice in relation to health of the community, given the importance of engagement and experience of store managers and owners in influencing a store's healthiness ${ }^{(7,19,20)}$. Databases searched included PubMed, EBSCOhost and Gale using keywords related to setting (e.g. supermarket, retail, food outlet, consumer environment), product (e.g. food, beverage, point-of-sale), store-based practices (e.g. price, availability, store manager, policy) and data collection method (e.g. measure, evaluate, survey, tool). Articles were screened by R.J. and C.B., and J.B. where consensus could not be reached. We included all peer-reviewed publications reporting development of, or outcomes related to, a tool measuring the store food retail environment and/or manager perspectives, including those identified by earlier systematic reviews ${ }^{(5,21)}$. Review papers, non-peerreviewed publications and manuscripts describing tools that measured customer perspectives only were excluded. We also searched reference lists of included articles, the grey literature including key websites and purposively sourced tools currently used in the NT to capture current measures used within the remote Aboriginal setting. The review process is outlined in the Preferred Reporting Items for Systematic Reviews and Meta-Analyses (PRISMA) flow chart (Fig. 1).

\section{Results}

Forty-seven tools to measure the in-store environment and/ or store manager perspectives were identified, most of which included assessment of stores in low-socioeconomic settings. All tools had accompanying articles describing their development and/or use. Four of the identified tools were developed in Australia, three of which were applied in capital cities and one in a rural location. All four of these tools measured product and/or price only ${ }^{(22-25)}$. Fifteen studies reported on tools that were adaptations of those previously developed, most commonly the Nutrition Environment Measurement Survey ${ }^{(26)}$. Table 1 provides a summary of aspects of the store environment assessed by the included studies/tools and examples of these; further detail is presented in online Supplemental Table 1.
Nearly all instruments ( $n$ 42, 89\%) included at least one measure of product, with availability being the most common element measured ( $n$ 39). Placement (shelf placement, in-store placement and/or shelf space) was measured by $66 \%$ of tools ( $n 31$ ), $64 \%$ ( $n$ 30) measured Price and $43 \%$ ( $n$ 20) measured Promotion (presence, type and/or location). Sixteen tools (34\%) measured elements of all four Ps. Five instruments (11\%) considered manager perspectives on the 4Ps and other aspects of the store such as staffing, procurement and administration. None of the tools contained a scoring component within the tool itself, although nineteen papers described the methods used to calculate an overall store score based on the data collected. Of the forty-three tools measuring 'Ps' (i.e. not solely manager interviews), $63 \%$ ( $n$ 27) had some reported measure of robustness, most commonly inter-rater reliability.

\section{Step 2. Stakeholder consultation}

\section{Methods}

Preliminary consultation with stakeholders occurred in February/March 2015 to determine initial interest and support for a store environment assessment tool. In August 2015 to May 2016, using a mix of purposive and snowball sampling, we conducted interviews with stakeholders representing diversity in roles, views, expertise and regions of the NT. The interviews were intended to determine the relevance of a set of measures identified from the literature review to the remote Aboriginal and Torres Strait Islander setting, and identify additional measures considered important to include in the proposed tool. Characteristics of participants are presented in Table 2.

A semi-structured interview guide was used to capture data on the following themes: perceptions of what comprises a 'healthy store' and how the 'healthiness' of a store could be measured; any tools used or known to exist not identified through the literature review; the perceived importance of the 4 P's and their sub-elements in contributing to a healthy store and whether retail practice relating to these should be captured by the proposed tool; application of the tool (i.e. potential users and frequency of use); and potential positive and/or negative impacts of the proposed tool. Interviews were conducted according to the interview guide, either by R.J. independently or with another member of the research team. Where practical, interviews were conducted in person (in-person interviews were conducted individually, or in small groups of two to three where people belonged to the same organisation). Where participants were unable to meet in person, telephone interviews were conducted ( $n 3$ ). Interviews were audio-recorded and later transcribed where verbal consent was received ( $n$ 14), or were otherwise scribed ( $n$ 20). Transcripts were sent to participants for their review and modification if required. Most were satisfied with the 


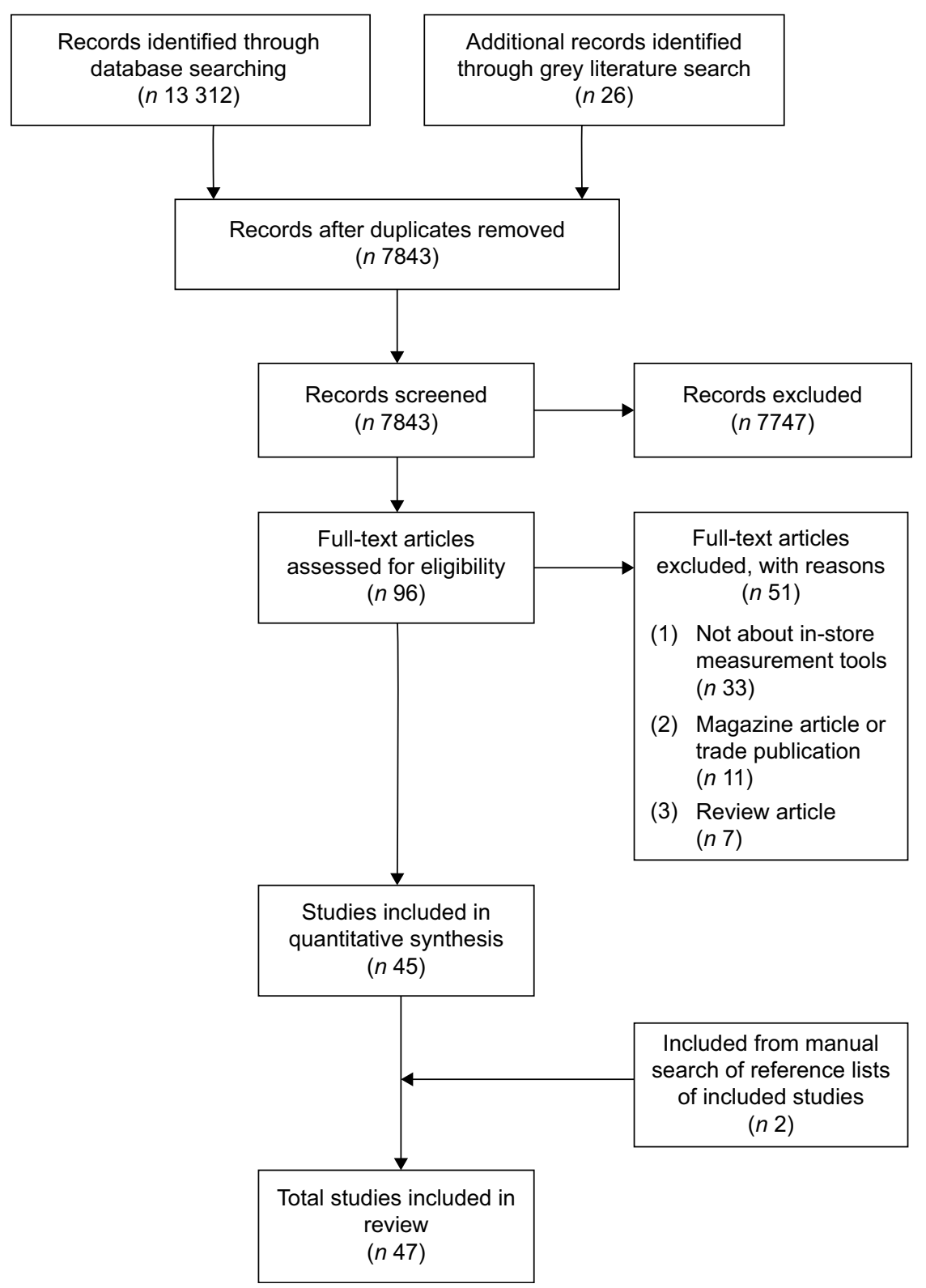

Fig. 1 PRISMA flow chart

Table 1 Aspects of the store environment assessed by the included studies/tools and examples of these

\begin{tabular}{|c|c|c|c|}
\hline $\begin{array}{l}\text { Element measured/ } \\
\text { feature of tool }\end{array}$ & $\begin{array}{l}\text { In } \% \text { of } \\
\text { tools }\end{array}$ & $n$ & Examples of content \\
\hline Product & 89 & 42 & $\begin{array}{l}\text { Variety (brands, pack sizes, types); Availability (presence/absence of item, empty shelves); } \\
\text { Quality (of fresh produce, expiry dates, nutrition criteria) }\end{array}$ \\
\hline Price & 64 & 30 & Per unit/weight, presence of price label, sale price, cheaper alternative \\
\hline Placement & 66 & 31 & $\begin{array}{l}\text { Prominence, number of facings, shelf-space, location of items relative to others, beverages } \\
\text { out of fridge, location in store, displays, items at registers }\end{array}$ \\
\hline Promotion & 43 & 20 & $\begin{array}{l}\text { Type and focus (e.g. product, health, price), target audience, prominence, content, location } \\
\text { in store }\end{array}$ \\
\hline Manager perspectives & 11 & 5 & $\begin{array}{l}\text { Experience, stocking practices and influencing factors, promotional practices, knowledge, } \\
\text { attitudes }\end{array}$ \\
\hline $\begin{array}{l}\text { Scoring method } \\
\text { described in text }\end{array}$ & $41^{*}$ & 19 & $\begin{array}{l}\text { Tally of items available, mean quality score, composite score considering all elements } \\
\text { (weighted or unweighted) }\end{array}$ \\
\hline Robustness measure & $63^{*}$ & 27 & $\begin{array}{l}\text { Reliability (inter-rater, test-retest, inter-method, internal consistency), Validity (face, content, } \\
\text { construct, convergent, discriminant) }\end{array}$ \\
\hline
\end{tabular}

${ }^{\star}$ Excludes tools which only measured manager perspectives. 
Table 2 Characteristics of interview participants

\begin{tabular}{lr}
\hline & Number \\
\hline Participant type & \\
Public Health Nutritionist & 14 \\
Store Board Director & 10 \\
Store Manager & 9 \\
Australian Government Stores Licencing Officer & 4 \\
Store Organisation Nutritionist & 3 \\
Store Organisation retail/merchandising & 2 \\
$\quad$ representative & 1 \\
Community-Based Worker & 1 \\
Northern Territory Department of Health Nutrition & \\
representative & \\
Organisation type & 18 \\
Store Organisation & 13 \\
State Government & 4 \\
Australian Government, Department of Prime Minister & 4 \\
$\quad$ \& Cabinet & 6 \\
Independently Owned Store & \\
Aboriginal Health Service & 3 \\
\hline
\end{tabular}

content and level of detail, though some participants made slight changes or additions.

Interview transcripts were de-identified and uploaded into NVivo (version 9). A codebook was developed which comprised a set of parent nodes based on the interview questions. Sub-nodes/themes were derived from the interview content following discussion and agreement between the research team. Interviews were coded by R.J. and a subsample by C.B. to ensure consistency.

\section{Results}

Thirty-four interviews were conducted with forty-four participants, who represented a range of roles, organisations and regions across the NT (Table 2). Table 3 shows the elements reported by stakeholders to be key factors in determining the healthiness of a store; product, placement and promotion were considered important contributors to the healthiness of a store by more than half of respondents, while other 'Ps' were less commonly raised. Interestingly, pricing-related factors were mentioned by only six respondents (18\%).

The majority of respondents felt that the proposed tool used either regularly or at a minimum of once per year would have benefits to their role, their organisation, the store and the wider community, through enabling (i) monitoring, evaluation and feedback around store practices, (ii) standardised in-store practices across remote stores to support healthy food purchases, (iii) engagement by PHN with store managers and owners and (iv) capacity building and teamwork among those concerned with nutrition improvement in remote communities.

\section{Step 3. Assessing whether existing tools meet identified needs}

Methods

Data on elements of each 'P' from the literature review and stakeholder consultation were mapped with the Good
Table 3 Elements of each 'P' considered by stakeholders to be key contributors to the healthiness of a store

\begin{tabular}{|c|c|}
\hline ‘P’ & Element \\
\hline Product (94 \%; $n$ 32) & $\begin{array}{l}\text { - Availability } \\
\text { - Variety } \\
\text { - Choice of both fresh produce and } \\
\text { healthy food }\end{array}$ \\
\hline Placement (53\%; $n$ 18) & $\begin{array}{l}\text { - More shelf space dedicated to } \\
\text { healthier products } \\
\text { - Healthier products at the front of the } \\
\text { store and displayed prominently }\end{array}$ \\
\hline Promotion (50\%; $n$ 17) & $\begin{array}{l}\text { - Up-to-date } \\
\text { - Interactive } \\
\text { - Prominent } \\
\text { - On healthy products only }\end{array}$ \\
\hline Place (41\%; $n$ 14) & $\begin{array}{l}\text { - Store cleanliness \& hygiene } \\
\text { practices } \\
\text { - Infrastructure } \\
\text { - Access to store }\end{array}$ \\
\hline Policy (26\%; $n$ 9) & $\begin{array}{l}\text { - Nutrition policies and their } \\
\text { development } \\
\text { - Food safety standards } \\
\text { - Policies covering employment, } \\
\text { pricing and trading hours }\end{array}$ \\
\hline People (24\%; $n$ 8) & $\begin{array}{l}\text { - Commitment from store managers } \\
\text { to health and nutrition } \\
\text { - Store owners and staff working } \\
\text { together } \\
\text { - Local employment and staff } \\
\text { capacity-building } \\
\text { - Local decision-making about the } \\
\text { store, } \\
\text { - Store working with supports such as } \\
\text { Public Health Nutritionists }\end{array}$ \\
\hline Price $(18 \% ; n 6)$ & $\begin{array}{l}\text { - Food affordability } \\
\text { - Display of prices }\end{array}$ \\
\hline $\begin{array}{l}\text { Financial and governance } \\
\text { practices }(12 \% ; n 4)\end{array}$ & $\begin{array}{l}\text { - Store board presence and } \\
\text { functioning } \\
\text { - Existence of financial structures } \\
\text { and practices } \\
\text { - Profitability and sustainability of the } \\
\text { store }\end{array}$ \\
\hline
\end{tabular}

Food Planning Tool best practice areas for the Food Businesses domain ${ }^{(7)}$. Information was summarised on (i) elements of each P; (ii) best practice associated with each element (e.g. how shelf space is measured) and (iii) existing measures of best practice/current practice (e.g. national guidelines, remote store policies).

\section{Results}

We confirmed that no existing tools comprehensively measured all 4Ps which were also specific to the remote Aboriginal community store setting, and thus none of these tools met identified needs. See Table 1 and online Supplemental Table 1 for components measured by existing tools, and Table 3 for examples of store components considered important by interview participants.

\section{Step 4. Tool development}

Methods

Measures from Step 3 were scrutinised for inclusion, taking into consideration: features commonly identified among 
stakeholders as important to measure, duplication with existing tools commonly used in this setting currently (e.g. Market Basket Survey), relevance to the remote store setting, detail and scope of the tool (i.e. allowing for rapid appraisal of best practice without being overly prescriptive of particular products or brands). Refinement of tool structure and content occurred iteratively prior to, during and post pilot stage.

\section{Results}

The developed Healthy Store Environment Tool (version 1) comprised an observational checklist (yes/no) of the 4Ps in relation to each of seven food categories. These categories were determined by taking into consideration priority food categories in remote stores as well as food groups from the Australian Guide to Healthy Eating ${ }^{(27)}$. Categories (sub-categories) were: Fruit \& Vegetables (fresh, frozen, canned, dried); Drinks (bottled water, sugar-sweetened beverages, juice, cordial); Snack Foods (healthier snacks, lollies, chocolate, chips, ice creams, sweet biscuits, cakes, savoury biscuits); Meals \& Convenience Foods (ready-toeat, heat-and-eat); Breads \& Cereals (bread, breakfast cereals, pasta, rice, noodles); Meat \& Seafood (refrigerated, frozen, canned, deli meats) and Dairy \& Eggs (milk, cheese, yoghurt, eggs). See online Supplementary File for a copy of the Healthy Store Environment Tool (version 1).

Food category product types were based on the Food Security Report Licence Compliance \& Store Audit tool ${ }^{(17)}$ and the types of foods and drinks available in remote stores, and included questions about healthier and less healthy options within each of the seven food categories; categorisation of healthiness was descriptive (e.g. lean meats) and/or based on nutrient criteria (e.g. (>15 g fibre/100 g) specified in the Market Basket Survey ${ }^{(18)}$ and Food Security Report Licence Compliance \& Store Audit Checklist $^{(17)}$. The Healthy Store Environment Tool considered both positive (e.g. healthier products available, placed prominently) and negative practices (e.g. promotion on sugar-sweetened beverages).

Questions directed to the store manager were included in the tool to provide context and additional information not obtained from observation of in-store practices. Eleven of these questions were related to the 4Ps, and six addressed the store manager's perceived importance of key principles relating to the store environment, rated on a five-point scale (not important - very important). These key principles included the role of the store environment in influencing food choice, store manager knowledge and understanding of healthy food, the existence of a nutrition policy and/or strategy, and store manager and staff engagement/interaction with store owners, the community and other services. The extent to which these occurred in the store was assessed on a five point-scale (not at all - a lot).

The tool included a summary section for the user to record the score for each food category and to record notes on proposed strategies discussed with the store manager. Instructions and definitions were included at the beginning of the tool.

\section{Step 5. Tool pilot}

\section{Methods}

A paper-based version of the Healthy Store Environment Tool (version 1) was piloted and tested for feasibility during September to October 2016 in nine remote community stores (six communities) in Central Australia and the Top End of the NT. Stores were selected to represent different organisational structures (store organisation, independently managed), size (small, large) and infrastructure (new building, sub-optimal/old building). We also considered existing relationships with communities/stores, the availability of stakeholders servicing these communities/ stores to participate in the pilot, the opportunity to visit the store with the stakeholder and receipt of support from each Store Board.

Following receipt of Store Board support, visits were arranged with the store manager and/or the PHN servicing the community. The tool was piloted independently by one each of a researcher (R.J. or C.B.) and tester (the store manager and/or PHN).

Testers ( $n$ 9) and researchers (R.J. and C.B.) recorded start and end times in use of the tool, to give an indication of time taken to complete. To determine acceptability and feasibility of the tool, testers completed a 'Post-Pilot Feasibility and Acceptability Assessment' to assess the following on a four-point scale (disagree strongly-agree strongly): practicality of time taken to complete the tool, comprehensiveness of the tool to assess 'healthiness' of the store environment, ease of use, ability of tool to facilitate feedback and discussion, clarity of tool instructions and relevance to work in their respective roles. Testers were also asked if they would use the tool again and, if so, how they would use it, and to provide any additional feedback. Responses were entered into a purpose-built spreadsheet.

After each pilot and feedback process, researchers and testers discussed specific considerations such as ambiguity of questions, and any discrepancies in responses. A descriptive assessment of agreement between researcher/tester pairs was made by comparing responses for each completed tool. Where there appeared to be consistently lower agreement (e.g. with the scoring component), this was considered along with stakeholder feedback when making further refinements to the tool.

\section{Results}

All testers ( $n$ ) r) responded favourably (i.e. agree or strongly agree) to all six Likert-scale questions: Testers agreed ( $n$ 5) or strongly agreed $(n 4)$ that the time taken to complete the tool was practical, that the tool was comprehensive (agree, $n$ 6; strongly agree, $n$ 3), easy to use (agree, $n$ 6; strongly 
agree, $n$ 3), enabled them to provide feedback and facilitated discussion with the store manager about store practice in relation to the 4Ps (agree, $n$ 6; strongly agree, $n 3$ ), the instructions on how to use the tool were clear (agree, $n$ 6; strongly agree, $n 3$ ), and that the tool was relevant to their work (strongly agree, $n 7$; agree, $n 2$ ).

Of the five testers that responded to the question asking whether they would use the Healthy Store Environment Tool again, four said yes and one said maybe, the latter suggesting that it should be combined with existing tools such as the NT Market Basket Survey. Seven testers responded to the question on how they would use the tool, with responses referring to frequency of use (monthly, quarterly, bi-annually, annually or at every visit) or purpose (to inform/incorporate into existing organisational tools, to provide a baseline measure of the in-store food retail environment and to ensure consistency in best practice to support healthy food purchases on changeover of store managers). From pilot feedback, stakeholders were supportive of the questions directed to the store managers and felt that their inclusion in the tool could be a way to engage store managers in transforming their stores to support healthy food purchases.

Additional feedback from testers suggested there would be benefit in developing an automated tool, particularly to address limitations associated with the paper-based instrument (e.g. skipping questions, subjectivity of the scoring component, interpretation of questions). As such, the refined tool was transitioned into a digital tool (mobile application), Store Scout.

\section{Step 6. Development of mobile application (app)}

\section{Methods}

We engaged a mobile application developer in 2017. Wireframes (sample screens) and a prototype were developed based on the paper version of the tool. Additional content/functions which were not practical or possible to include in the paper version of the tool were developed for the mobile app. These included pop-up 'tool-tips' next to measurement items to provide additional information and definitions (for instance, nutrient criteria or a definition of shelf space), automated scoring and summary results to enable immediate feedback.

Further, questions are forced-response, meaning that the survey cannot be completed without all questions being answered, thus avoiding missing data. The scoring component is automated within the Store Scout app, enabling immediate feedback to store managers through graphically presenting scores for the overall store, each food category and the 4Ps within each food category. It includes a function where users can generate an action plan with the store manager, with suggested strategy options that are automatically identified based on tool responses (e.g. if there is confectionery in the fresh produce section, a suggested strategy option to remove the confectionery from that location is shown and can be selected from a list).

\section{Results}

The Store Scout app supports rapid appraisal of the in-store food environment, and immediate feedback as scores (automated scoring) and suggested strategies for improvement (action plan). The app includes nine sections: Seven sections related to distinct categories of food and drink, Manager Perspectives (both of which reflect the content of the paper-based tool), and Action Plan. Users are guided through a series of screens, answering yes/no, tick-box and free-text questions related to the 4Ps across each of the seven food categories. All yes/no questions must be completed to move to the next screen, and all food and drink sections must be completed to complete the survey. Manager perceptions and Action plan sections are not compulsory to complete the survey and do not contribute to scoring.

Scoring is calculated from 199 yes/no questions, each of which is worth one possible point. All scoring questions are forced-response (user must answer the question to move through the survey), except for six scoring questions which are only shown if the answer to a previous non-scoring measurement item was 'yes'. Therefore, there are 193-199 scoring questions (and the same number of possible points) across the seven categories, with varying numbers in each category: Breads \& Cereals 20; Dairy \& Eggs 29; Drinks 28; Fruit \& Vegetables 30; Meals/Convenience Foods 24-30; Meat \& Seafood 21; Snack Foods 41. Practices related to both healthy products and unhealthy products contribute to scoring. For practices likely to encourage purchases of healthy products (e.g. 'Fresh Fruit at or near checkout') or discourage purchases of unhealthy products (e.g. 'Limited range of lollies'), a point is awarded for a 'yes' response. For practices likely to encourage purchases of unhealthy (or less healthy) products ('Lollies, chocolate \& chips at or near checkouts'), a point is awarded for a 'no' response. Scores (range from 0 to 100; higher more 'healthenabling') are calculated for each of the seven food and drink categories as a percentage of total possible points averaged across the seven categories to give an overall score $^{(28)}$.

A complementary online portal is under construction, which will enable users to access reports of store progress longitudinally. Reliability, utility and construct validity of measurements using the Store Scout App are reported elsewhere $^{(28)}$.

\section{Discussion}

We developed a purpose-built decision-support tool to objectively assess the in-store food retail environment in remote Australian Aboriginal and Torres Strait Islander 
communities, through a systematic and rigorous process drawing on a review of existing tools globally and locally, and expert opinion and experience. The Healthy Store Environment Tool and subsequent Store Scout mobile app address an unmet need; to the best of our knowledge, there is no existing tool that measures the consumer environment through addressing all 4Ps whilst also incorporating manager perspectives and immediate feedback. Existing tools largely focus on practice relating to price and product ${ }^{(29)}$.

In addition to the observational checklist, key features of the tool include the manager questions and feedback sections. Consistent with previous findings ${ }^{(7,19,20)}$, during our consultation, stakeholders emphasised the importance of engagement and experience of store managers and owners for influencing a store's healthiness, and that the relationship and engagement of store managers and owners with the community are also key.

In line with our objectives for the tool, the feedback function was designed to stimulate discussion with store managers, both to celebrate existing positive practice and to discuss strategies for improvement, and was found to achieve this during testing. All testers agreed or strongly agreed that the tool enabled them to provide feedback and helped facilitate discussion with the store manager about the store environment, and store managers were receptive to having these discussions with testers. Indeed, some store managers requested copies of the completed tool and feedback (including suggested strategies) following the pilot.

To improve acceptability, feasibility and reliability, we transitioned the paper-based tool into a mobile app. Following completion of the steps described in this paper, we evaluated the reliability (inter-rater reliability and internal consistency), utility (distribution of scores) and construct validity (score by store type) of measurements using the Store Scout mobile app in two samples: twenty remote Indigenous community stores in the NT and Northern Queensland, and thirty-four metropolitan stores in Brisbane, the capital city of Queensland, Australia (including supermarkets, convenience stores and petrol stations $)^{(28)}$. We found good to very good inter-rater reliability of most measurement items, high inter-rater agreement between scores, and high internal consistency of measurements ${ }^{(28)}$. We also found evidence that the scoring system could capture differences by type of store in line with previous evidence, giving evidence of construct validity $^{(28)}$.

There is increasing momentum globally to transform food retail environments to support healthy eating and combat overweight and obesity and diet-related disease. We previously demonstrated that stakeholders with a role in improving the community food system in remote Aboriginal Australian communities value decision-support tools that can support them perform best practice in their areas of influence as part of continuous improvement ${ }^{(7)}$. Retailers in the remote context, as in urban supermarkets, use marketing strategies related to the 4Ps to maximise sales as the majority of consumer purchase decisions are made at the point-of-purchase (i.e. at the shelf, end of aisle and check out ${ }^{(30)}$. In the remote setting, these strategies are also used to encourage healthy foods and/or discourage less healthy foods to improve population health and have been shown to impact on customer food purchases ${ }^{(31-33)}$. For example, stores may have a fruit bowl at the counter and/or confectionery-free counters or confectionery placed above 'eye level' of children ${ }^{(7,19)}$. An emerging area of research is investigating how these retail practices can be effectively applied to promote healthy food consumer choices in stores and supermarkets ${ }^{(4,34,35)}$.

The tool reported herein complements our Good Food Planning Tool and the Good Food systems continuous improvement approach through providing an objective rapid appraisal of the healthiness of the store environment. Its use over time can contribute to scale-up of best practice evidence and a continuous approach to incremental nutrition improvement in remote Australian Aboriginal and Torres Strait Islander communities. Whilst the Healthy Store Environment Tool, and thereafter Store Scout app, was initially developed for the remote Australian Aboriginal and Torres Strait Islander Australian community store context, it has potential applicability to other similar retail settings, as demonstrated through pilot testing in urban stores ${ }^{(28)}$, and provides a tool which enables a comprehensive assessment of all 4Ps.

\section{Limitations}

The systematic review may not have captured all existing tools; however, we comprehensively searched peerreviewed publications and grey literature to ensure we captured those tools where sufficient detail was available on their development and evaluation. As this is a fastmoving field, it is possible that further tools have been developed since the search was conducted.

All interviews were conducted according to a preestablished interview guide. We allowed flexibility in how interviews were conducted and recorded to ensure we could include a diverse range of stakeholders across a range of different locations, within their schedules, and while respecting wishes to opt out of audio-recording. Less than half of the interviews were recorded (thereby relying on the interviewer to take comprehensive notes); however, all participants were sent a copy of their interview to verify the data collected and most responded with minimal change requested and/or confirmation of content.

We attempted to minimise sample bias by selecting stores for the pilot that were in different regions of the NT, of different sizes and that represented the different store ownership and/or management models in the NT. The store owners and managers interviewed had diverse roles, most had worked in and/or with numerous communities and drew from their broader retail/community 
experience in interviews. Tool structure and content were also informed by literature review. These factors make it less likely that broader sampling would have led to differences in the content and structure of the tool.

It is important to note that the tool was not designed to monitor food price, but instead measures practices relating to price promotion. Other tools comprehensively monitor food prices in Australia in both remote and non-remote settings ${ }^{(18,36)}$. To provide a rapid appraisal, the tool uses mostly yes/no questions to indicate whether or not the store is in line with best practice; therefore, more detailed data that may be of interest for monitoring aspects of the food environment (e.g. metres of shelf space, number of bays, extensive list of available products) are not captured. A unique aspect of this tool is that it can provide a measure of practice across the 4 P's for a broad range of healthy and unhealthy products in $<30$ min (median $25 \mathrm{~min}$, range 10-40, in thirty-four metropolitan supermarkets, petrol stations and convenience stores) while also enabling immediate feedback ${ }^{(28)}$.

We have found Store Scout to have relevance for the broader non-remote food retail setting ${ }^{(28)}$. Outside of Australia, Store Scout would require adaptation due to potential differences in food and retail terminology and differences in national dietary guidelines. Revision of Store Scout will be required to stay relevant to food supply changes (e.g. reformulation) and best practice evidence.

\section{Conclusion}

A decision-support tool to comprehensively and rapidly appraise the in-store food retail environment in remote Aboriginal and Torres Strait Islander Australian communities is required to support stores, and those who work with stores, to implement practices to encourage healthier food purchasing and improved population diet. Our extensive consultation and iterative process of development has resulted in an innovative product to meet this current unmet need and to provide a decision-support tool that enables rapid appraisal of and feedback on the healthiness of the in-store environment that has potential for use in non-remote food retail settings, at local and international levels.

\section{Acknowledgements}

Acknowledgements: The authors thank the Store Committees, Companies and managers who enabled us to pilot the tool in their stores; the Public Health Nutritionists and store managers who gave their time to test the tool; and all stakeholders for their time, advice, input and enthusiasm throughout the process of developing the tool. Financial support: This work was supported by funding from the National Health and Medical Research
Council of Australia (ID631947). J.B. was supported by a Future Leader Fellowship from the National Heart Foundation of Australia (100085). E.M. was supported by a co-funded National Health and Medical Research Council and Australian Heart Foundation Early Career Fellowship (101286). The funders had no role in the study design, collection, analysis or interpretation of data, writing of the report or the decision to submit the article for publication. Conflict of interest: None. Authorship: J.B. formulated the research question. R.J., C.B. and J.B. developed the tool. R.J. and C.B. conducted the stakeholder consultation and pilot. All authors contributed to interpretation of results. R.J. drafted the manuscript with review by J.B., C.B. and EM. All authors approved the final version of the manuscript. Ethics of buman subject participation: This study was conducted according to the guidelines laid down in the Declaration of Helsinki, and all procedures involving study participants were approved by the Human Research Ethics Committee of the Northern Territory Department of Health and Menzies School of Health Research (HREC 2015-2459) and the Central Australian Human Research Ethics Committee (HREC-16391). Written informed consent was obtained from all subjects. Verbal consent to audio record interviews was witnessed and formally recorded.

\section{Supplementary material}

For supplementary material accompanying this paper visit https://doi.org/10.1017/S1368980020002025

\section{References}

1. Glanz K, Sallis J, Saelens B et al. (2005) Healthy nutrition environments: concepts and measures. Am J Health Promot 19, 330-333.

2. Ni Mhurchu C, Vandevijvere S, Waterlander W et al. (2013) Monitoring the availability of healthy, unhealthy foods, nonalcoholic beverages in community, consumer retail food environments globally. Obes Rev 14, Suppl. 1, 108-119.

3. Glanz K, Bader MD \& Iyer S (2012) Retail grocery store marketing strategies and obesity. Am J Prev Med 42, 503-512.

4. Cameron AJ, Charlton E, Ngan WW et al. (2016) A systematic review of the effectiveness of supermarket-based interventions involving product, promotion, or place on the healthiness of consumer purchases. Curr Nutr Rep 5, 129-138.

5. Kelly B, Flood VM \& Yeatman H (2011) Measuring local food environments: an overview of available methods and measures. Health Place 17, 1284-1293.

6. Gittelsohn J \& Sharma S (2009) Physical, consumer and social aspects of measuring the food environment among diverse low-income populations. Am J Prev Med 36, Suppl. 4, S161-S165.

7. Brimblecombe J, van den Boogaard C, Wood B et al. (2015) Development of the good food planning tool: a food system approach to food security in indigenous Australian remote communities. Health Place 34, 54-62.

8. Australian Bureau of Statistics (2018) 3238.0.55.001 - Estimates of Aboriginal and Torres Strait Islander Australians, June 2016. 
Available at https://www.abs.gov.au/ausstats/abs@.nsf/mf/ 3238.0.55.001 (accessed November 2019).

9. Arnhem Land Progress Aboriginal Corporation (n.d.) ALPA Health \& Nutrition Policy. Available at http://www.alpa.asn. au/ (accessed February 2018).

10. Outback Stores (n.d.) Health \& Nutrition. Available at http:// outbackstores.com.au/impact/health-nutrition/ (accessed February 2018).

11. Ferguson M, O'Dea K, Holden S et al. (2017) Food and beverage price discounts to improve health in remote aboriginal communities: mixed method evaluation of a natural experiment. Aust N ZJ Public Health 41, 32-37.

12. Lee A, Rainow S, Tregenza J et al. (2016) Nutrition in remote Aboriginal communities: lessons from Mai Wiru and the Anangu Pitjantjatjara Yankunytjatjara Lands. Aust N Z J Public Health 40, S81-S88.

13. National Health and Medical Research Council (2017) Discretionary Food and Drink Choices. Available at https://www.eatforhealth.gov.au/food-essentials/discretionaryfood-and-drink-choices (accessed July 2019).

14. Food and Agriculture Organisation of the United Nations (2016) Influencing Food Environments for Healthy Diets. Available at http://www.fao.org/3/a-i6484e.pdf (accessed July 2019).

15. Australian Institute of Health and Welfare (2016) Australian Burden of Disease Study: Impact and Causes of Illness and Death in Aboriginal and Torres Strait Islander People in 2011. Available at https://www.aihw.gov.au/reports/ burden-of-disease/australian-bod-study-2011-indigenousaustralians/contents/table-of-contents (accessed February 2018).

16. Australian Government (2012) Stronger Futures in the Northern Territory Act 2012. Available at https://www. legislation.gov.au/Details/C2012A00100 (accessed February 2018).

17. Department of Prime Minister \& Cabinet (2014) Food Security Report Licence Compliance \& Store Audit.

18. Northern Territory Department of Health (n.d.) Northern Territory Market Basket Survey. Available at http://digital library.health.nt.gov.au/prodjspui/simple-search?query $=\% 28$ \%28title\%3Amarket+title\%3Abasket\%29\%29\&from_advanced= true \&conjunction $2=\mathrm{AND} \&$ field $3=\mathrm{ANY} \&$ field $2=\mathrm{ANY} \&$ conjunc tion $1=$ AND\&field $1=$ title\&query $1=$ market+basket\&query $2=$ \&query3= (accessed January 2018).

19. Brimblecombe J, Bailie R, van den Boogaard C et al. (2017) Feasibility of a novel participatory multi-sector continuous improvement approach to enhance food security in remote Indigenous Australian communities. SSM Popul Health 3, 556-576.

20. Lee AJ, Bonson APV \& Powers JR (1996) The effect of retail store managers on Aboriginal diet in remote communities. Aust N Z J Public Health 20, 212-214.

21. McKinnon RA, Reedy J, Morrissette MA et al. (2009) Measures of the food environment: a compilation of the literature, 1990-2007. Am J Prev Med 36, S124-S133.

22. Giskes K, Van Lenthe F, Brug J et al. (2007) Socioeconomic inequalities in food purchasing: the contribution of respondent-perceived and actual (objectively measured) price and availability of foods. Prev Med 45, 41-48.
23. Ball K, Timperio A \& Crawford D (2009) Neighbourhood socioeconomic inequalities in food access and affordability. Health Place 15, 578-585.

24. Winkler E, Turrell G \& Patterson C (2006) Does living in a disadvantaged area entail limited opportunities to purchase fresh fruit and vegetables in terms of price, availability, and variety? Findings from the Brisbane Food Study. Health Place 12, 741-748.

25. Boylan S, Innes-Hughes C, Lobb E et al. (2011) Measuring Rural Food Environments within Murrumbidgee Health Network NSW: methodology. Available at https://ses.library. usyd.edu.au//bitstream/2123/8759/1/MeasRuralFood Enviros_methodology_030511.pdf (accessed February 2018).

26. Glanz K, Sallis JF, Saelens BE et al. (2007) Nutrition Environment Measures Survey in Stores (NEMS-S): development and evaluation. Am J Prev Med 32, 282-289.

27. National Health and Medical Research Council (2013) Australian Guide to Healthy Eating. https://www. eatforhealth.gov.au/guidelines/australian-guide-healthyeating (accessed January 2018).

28. McMahon E, Jaenke R \& Brimblecombe J (2020) Reliability, utility and construct validity of measurements using a mobile app to rapidly appraise the in-store food environment. JMIR mHealth uHealth. Published online: 24 March 2020. doi: 10. 2196/16971.

29. Love P, Whelan J, Bell C et al. (2019) Measuring rural food environments for local action in Australia: a systematic critical synthesis review. Int J Environ Res Public Health 16, 2416

30. Inman JJ, Winer RS \& Ferraro R (2009) The interplay among category characteristics, customer characteristics, and customer activities on in-store decision making. J Mark 73, 19.

31. Butler R, Tapsell L \& Lyons-Wall P (2011) Trends in purchasing patterns of sugar-sweetened water-based beverages in a remote Aboriginal community store following the implementation of a community-developed store nutrition policy. Nutr Diet 68, 115-119.

32. Scrimgeour D, Rowse T \& Knight S (1994) Food-purchasing behaviour in an Aboriginal community. 2. Evaluation of an intervention aimed at children. Aust J Public Health 18, 67-70.

33. Brimblecombe J, Ferguson M, Chatfield MD et al. (2017) Effect of a price discount and consumer education strategy on food and beverage purchases in remote Indigenous Australia: a stepped-wedge randomised controlled trial. Lancet Public Health 2, e82-e95.

34. Liberato SC, Bailie R \& Brimblecombe J (2014) Nutrition interventions at point-of-sale to encourage healthier food purchasing: a systematic review. BMC Public Health 14, 919 .

35. Brimblecombe J, Ferguson M, McMahon E et al. (2019) Reducing retail merchandising of discretionary food and beverages in remote Indigenous community stores: protocol for a randomized controlled trial. JMIR Res Protoc 8, e12646.

36. Lee AJ, Kane S, Lewis M et al (2018) Healthy diets ASAP Australian Standardised Affordability and Pricing methods protocol. Nutr J 17, 88. 